\title{
Internet Gaming Disorder and Its Associated Personality Traits: A Systematic Review Using PRISMA Guidelines
}

\section{Şerife Inci Şalvarlı ${ }^{1} \cdot$ Mark D. Griffiths $^{2}$ iD}

Published online: 18 April 2019

(C) The Author(s) 2019

\begin{abstract}
For most individuals, videogame playing is a fun and enjoyable activity that brings many benefits. However, for a small minority, the activity can be problematic and has led to much research into "gaming disorder." In explanations concerning the contributory factors to gaming disorder, personality traits have been increasingly studied. The present paper carried out a systematic review of available literature using Preferred Reporting Items for Systematic Reviews and Meta-analysis (PRISMA) guidelines. The inclusion criteria were (i) publication date between 2000 and 2018, (ii) being an empirical study, (iii) written in English and Turkish languages (the two languages spoken by the authors), (iv) published in a scholarly peerreviewed journal, and (v) conducted an assessment of IGD and personality traits objectively. Studies were excluded from the review if they were (i) single-case studies, (ii) unpublished thesis and dissertation studies, and (iii) not published in a peer-reviewed journal. Following these procedures, 21 eligible empirical studies were included. Results demonstrated that 24 distinct personality traits had been examined in relation to IGD and that some of these traits were demonstrated as risk factors for gaming addiction (although not always in the same direction).
\end{abstract}

Keywords Gaming psychology · Gaming disorder · Gaming addiction · Personality · Big five

Videogame playing is a popular leisure activity around the world, but in a small minority of cases, it can affect individuals' lives in negative ways such as addiction (Király et al. 2015).

Mark D. Griffiths

mark.griffiths@ntu.ac.uk

Șerife İnci Șalvarlı

inci.salvarli@deu.edu.tr

1 Psychology Department, Faculty of Letters, Dokuz Eylül University, Doğuș Street, 35390 İzmir, Turkey

2 International Gaming Research Unit, Psychology Department, Nottingham Trent University, 50 Shakespeare Street, Nottingham NG1 4FQ, UK 
Research examining the negative impact of gaming has progressively increased over the past decade along with problematic use of other online applications (van Rooij et al. 2010), and in 2013, Internet Gaming Disorder (IGD) was recognized by the American Psychiatric Association (2013). According to Entertainment Software Association (2017), the prevalence of American households that are home to an individual who regularly plays videogames increased by $65 \%$. In addition, the stereotypical idea of a gamer being an adolescent male is no longer valid (Kuss and Griffiths 2012) given that $31 \%$ of gamers are adult women and $18 \%$ of gamers are boys under age 18 years, and the average age of gamers is now 35 years (Entertainment Software Association 2017). Saunders et al. (2017) concluded that the prevalence of IGD ranged from 0.7 to $27.5 \%$ in 37 cross-sectional studies. Prevalence rates among nationally representative samples have also been varied, but the range is much lower. These include $1.4 \%$ of Norwegian adult gamers aged 16-74 years (Wittek et al. 2016), 1.6\% of seven European countries' youth aged 14-17 years (Müller et al. 2015), 4.3\% of Hungarian adolescents aged 15-16 years (Király et al. 2014), 5.5\% of German adolescents aged 1320 years (Rehbein et al. 2015), 8.5\% of American youth aged 8-18 years (Gentile 2009), and $17 \%$ of Iranian youth aged 14-15 years (Zamani et al. 2010). In addition to the time and effort spent playing videogames, a problematic gamer's physical and psychological well-being can be affected seriously (Király et al. 2015). Those with IGD can experience irritability, dissatisfaction, annoyance, and/or sadness as a consequence of gaming and can also cause such individuals to experience sleep and eating problems, backaches, headache, and fatigue (Király et al. 2014). These findings demonstrate the importance of continued research in the area.

Researchers have adopted a variety of terminologies to conceptualize disordered video gaming due to its detrimental effects, including computer addiction (Young et al. 1999), problematic videogame playing (Tejeiro Salguero and Morán 2002), videogame addiction (Griffiths and Davies 2005), pathological videogame use (Gentile 2009), Internet gaming addiction (Kuss and Griffiths 2012), and problematic online gaming (Demetrovics et al. 2012). The use of many different terminologies arguably makes it difficult to establish a unique clinical structure and determine the etiology of the disorder. Consequently, Internet Gaming Disorder (IGD) was included in Section 3 ("Emerging Measures and Models") in the latest (fifth) edition of the Diagnostic and Statistical Manual of Mental Disorders (DSM-5) (American Psychiatric Association 2013). IGD has been defined as a:

...persistent and recurrent engagement in videogames, often with other players, leading to clinically significant impairments or distress as indicated by five (or more) of the following nine criteria in a 12-month period: (1) preoccupation with games; (2) withdrawal symptoms when gaming is taken away; (3) tolerance, resulting in the need to spend increasing amounts of time engaged in games; (4) unsuccessful attempts to control participation in games; (5) loss of interest in previous hobbies and entertainment as a result of, and with the exception of, games; (6) continued excessive use of games despite knowledge of psychosocial problems; (7) deceiving family members, therapists, or others regarding the amount of gaming; (8) use of games to escape or relieve negative moods; and (9) jeopardising or losing a significant relationship, job, or education or career opportunity because of participation in games (APA 2013, p. 795).

Despite the diagnostic criteria of IGD being determined, there is still a need to delineate a comprehensive etiopathological model integrating different findings to define the development and maintenance of IGD (Müller et al. 2014). Therefore, cross-cultural reliability and validity 
of diagnostic criteria, prevalence of the disorder cross-culturally, associated biological structures, and risk factors require further investigation (Petry and O'Brien 2013).

The structural characteristics of the games (Griffiths and Nuyens 2017), as well as gamers' motivations such as coping with negative emotions, achievement (advancement and competition), socializing, and immersion (role-playing and escapism), are frequently cited as factors in the etiology of IGD (Kuss 2013). In addition, personality traits also appear to be important determinants in the enduring disposition of IGD and with controlling psychosocial, executive, and motivated behaviors (Kim et al. 2016). Scholars have considered that personality determinants of an individual's behavior (McCrae and Costa 1987) are closely associated with addictive behaviors (Floros and Siomos 2014). For instance, introverted individuals are more likely to be engaged in addictive behaviors in general (Landers and Lounsbury 2006). Introverted individuals use the virtual environment as a way of hiding or changing their identities, creating a new life style, preventing the likelihood of being ridiculed and rejected, and making social relationships (McKenna and Bargh 2000). These kinds of activities might make individuals more dependent on the Internet (McKenna and Bargh 2000). Landers and Lounsbury (2006) noted that individuals with low conscientiousness scores display higher levels of Internet use due to the unstructured procedures and regulations of virtual environments. A meta-analysis by Kayiş et al. (2016) examined the relationship between the big five personality traits and Internet addiction. It was reported that Internet addiction was negatively related with conscientiousness, extraversion, openness to new experiences, and agreeableness, and positively related with neuroticism. The largest effect size was found with conscientiousness, and the smallest effect size was found with openness to new experiences. Similarly, some personality traits may cause individuals to value specific features of games, increase motivation for playing games, and become addicted to gaming (Park et al. 2011). Stopfer et al. (2015) stated that while gaming motivation for narcissism was associated with having a talked-about subject and improving avatar's abilities, extraversion and agreeableness were correlated with gaining money. However, Park et al. (2011) claimed that none of the big five personality traits predict preference for specific genres of online games and overall game playing time. In addition to the studies about time spent and frequency of online gaming, the number of studies examining personality traits and IGD has also increased. However, to the authors' knowledge, there has never been a review paper examining the relationship between personality factors and IGD. Consequently, the present paper synthesizes the available literature utilizing the Preferred Reporting Items for Systematic Reviews and Meta-analysis (PRISMA) guidelines.

\section{Method}

\section{Eligibility Criteria}

All studies assessing the phenomenon of IGD and its related personality traits were eligible for review. The inclusion criteria were (i) publication date between 2000 and 2018, (ii) being an empirical study, (iii) written in English and Turkish languages (the two languages spoken by the authors), (iv) published in a scholarly peer-reviewed journal, and (v) conducted an assessment of IGD and personality traits objectively. 
Studies were excluded from the review if they were (i) single-case studies, (ii) unpublished thesis and dissertation studies, and (iii) not published in a peer-reviewed journal.

\section{Information Sources and Search}

A literature search was conducted via EBSCO (which included the following academic databases: Academic Search Complete, PsycARTICLES, and PsycINFO), Web of Science, PubMed, ScienceDirect, and Wiley Online Library. Several searches in the stated electronic databases were conducted during November 2018 using the following search terms: (Internet OR video OR computer) AND game OR gaming (addict* OR depend* OR disorder) AND personality*.

\section{Study Selection and Data Collection Processes}

After the initial literature searches conducted, the title and abstract of each study were screened and then potentially relevant studies were further assessed for eligibility. The detailed information about study selection process is provided in the PRISMA flow diagram (Fig. 1). In the process of assessing risk of bias in each study, sampling bias and measurement bias were also assessed.

\section{Results}

\section{Study Selection}

A total of 1980 studies (Web of Science, $n=732$; EBSCO, $n=564$; PubMed, $n=227$; Wiley Online Library, $n=44$, ScienceDirect, $n=415$ ) were identified via the initial search process. After the title and abstract of each study was examined, 1936 studies were excluded due to unsuitability for the present review. A further 20 studies were excluded due to duplication $(n=$ 17 ) and only having an abstract $(n=3)$. Consequently, a total of 30 studies were selected for eligibility phase. Of these, a total of nine studies were excluded for language issues $(n=3)$, being unpublished dissertation $(n=2)$, single-case reports $(n=1)$, assessing the overall game playing time as dependent variable $(n=2)$, and IGD not measured objectively $(n=1)$. Following these procedures, 21 eligible empirical studies were included in present review.

\section{Study Characteristics}

Information about the general characteristics and main methodological properties of all included 21 studies can be found in Tables 1 and 2 .

\section{Country in which the Data Were Collected}

Regarding the geographic characteristics of the included studies, five studies were from Germany (Borzikowsky and Bernhardt 2018; Braun et al. 2016; Laier et al. 2018; Müller et al. 2014; Walther et al. 2012), three were from South Korea (Kim et al. 2008; Kim et al. 2016; Lee et al. 2017), two from Spain (Gonzalez-Bueso et al. 2018; Torres-Rodríguez et al. 2018), two from China (Hu et al. 2017; Li et al. 2016), two from the UK (Collins et al. 2012; 


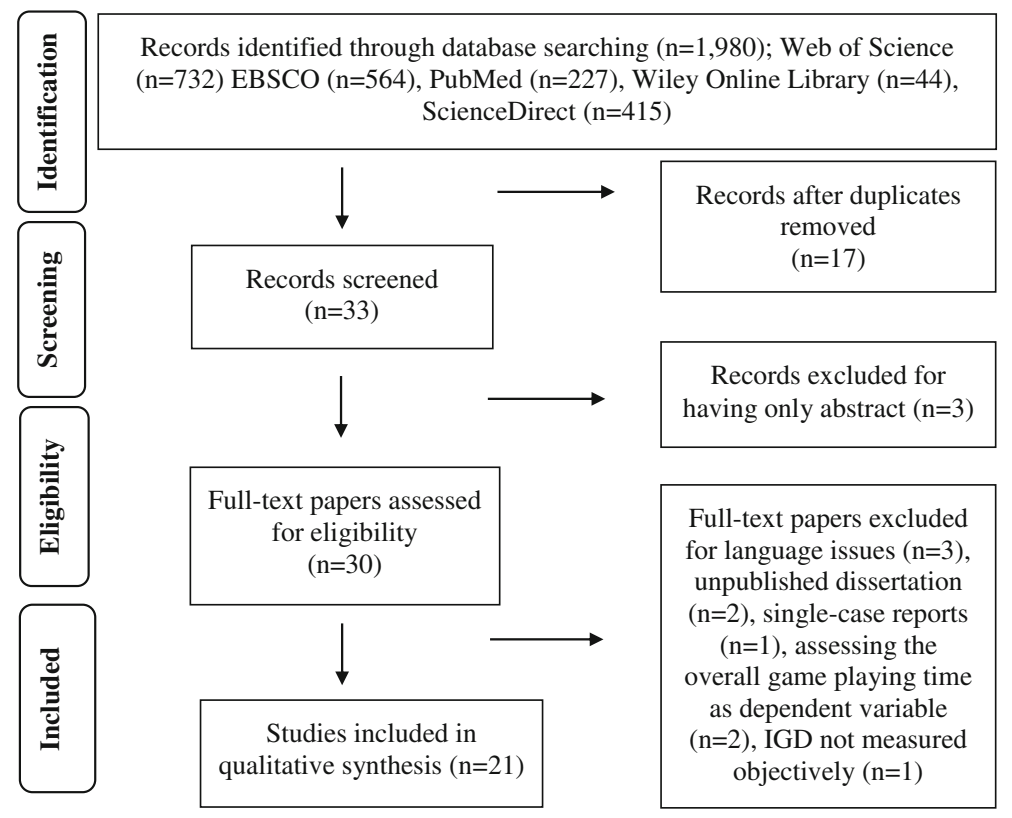

Fig. 1 PRISMA flow diagram of paper selection process used in the present study

Mehroof and Griffiths 2010), one from Turkey (Kurcaburun et al. 2018), one from Belgium (Schimmenti et al. 2017), one from Norway (Wittek et al. 2016), one from Hong Kong (Wang et al. 2015), and one from Taiwan (Chiu et al. 2004). Additionally, there were two crosscultural studies; the first one collected data from Germany, Austria, and Switzerland (Lehenbauer-Baum and Fohringer 2015), the second collected data from USA, Canada, Australia, New Zealand, and European Countries (Charlton and Danforth 2010).

\section{Participants}

The reviewed studies included a total of 16,536 participants. The vast majority of the included studies recruited more male participants $(n=11,204 ; 67.76 \%)$ than female participants $(n=5331 ; 32.24 \%)$. All the studies included adult samples apart from seven studies that included adolescent samples (Gonzalez-Bueso et al. 2018; Hu et al. 2017; Kim et al. 2016; Li et al. 2016; Torres-Rodríguez et al. 2018; Walther et al. 2012; Wang et al. 2015). Seven studies comprised student samples (Chiu et al. 2004; Hu et al. 2017; Kim et al. 2016; Li et al. 2016; Mehroof and Griffiths 2010; Walther et al. 2012; Wang et al. 2015); four studies included outpatients (Gonzalez-Bueso et al. 2018; Lee et al. 2017; Müller et al. 2014; Torres-Rodríguez et al. 2018); nine studies included gamers (Borzikowsky and Bernhardt 2018; Charlton and Danforth 2010; Hu et al. 2017; Kircaburun et al. 2018; Kim et al. 2008; Laier et al. 2018; Lehenbauer-Baum and Fohringer 2015; Schimmenti et al. 2017; Wittek et al. 2016); and with the exception of three studies (Hu et al. 2017; Laier et al. 2018; Wittek et al. 2016), all studies that included gamers comprised Massively-Multiplayer Online Role-Playing Games (MMORPGs) gamers. 







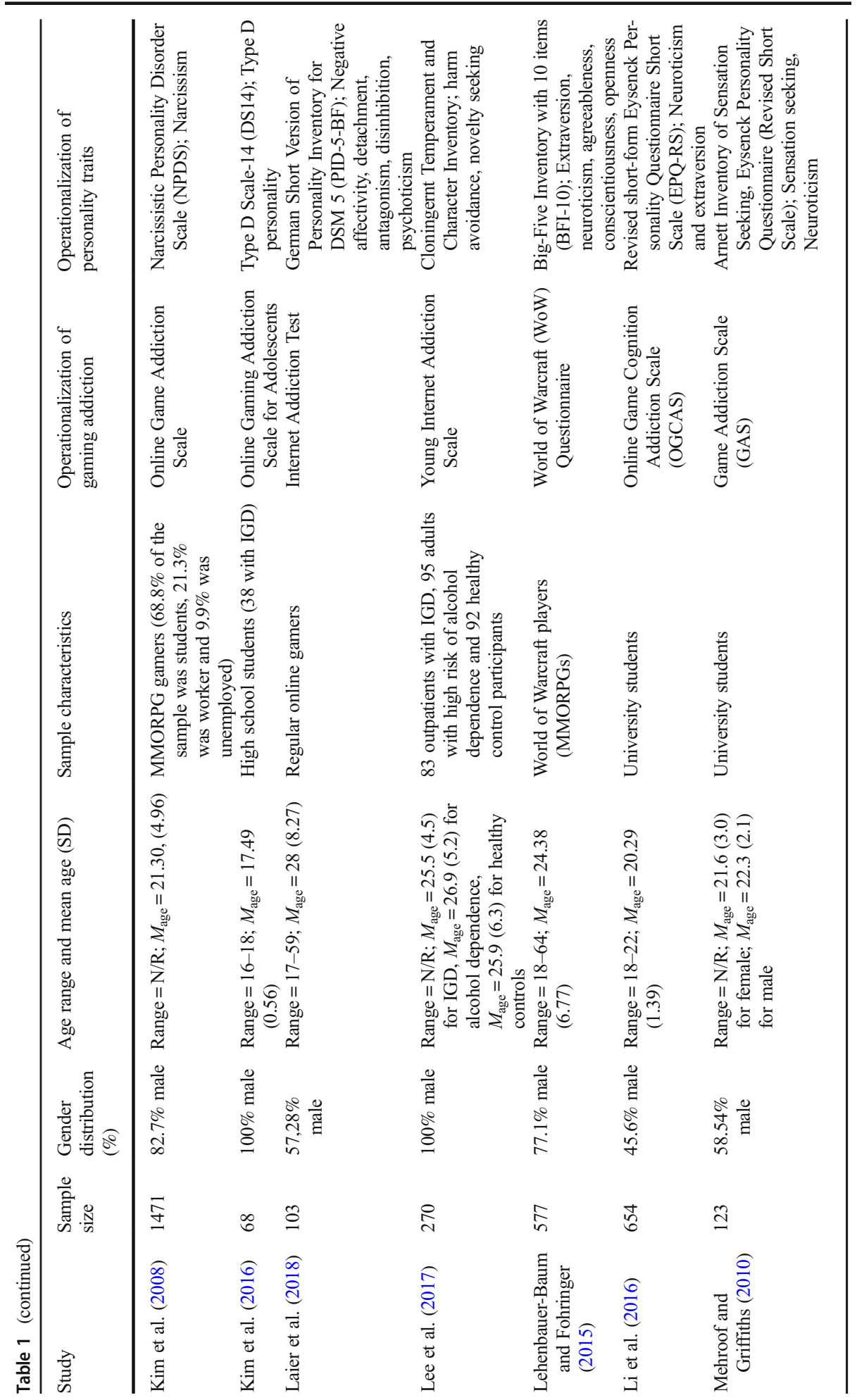




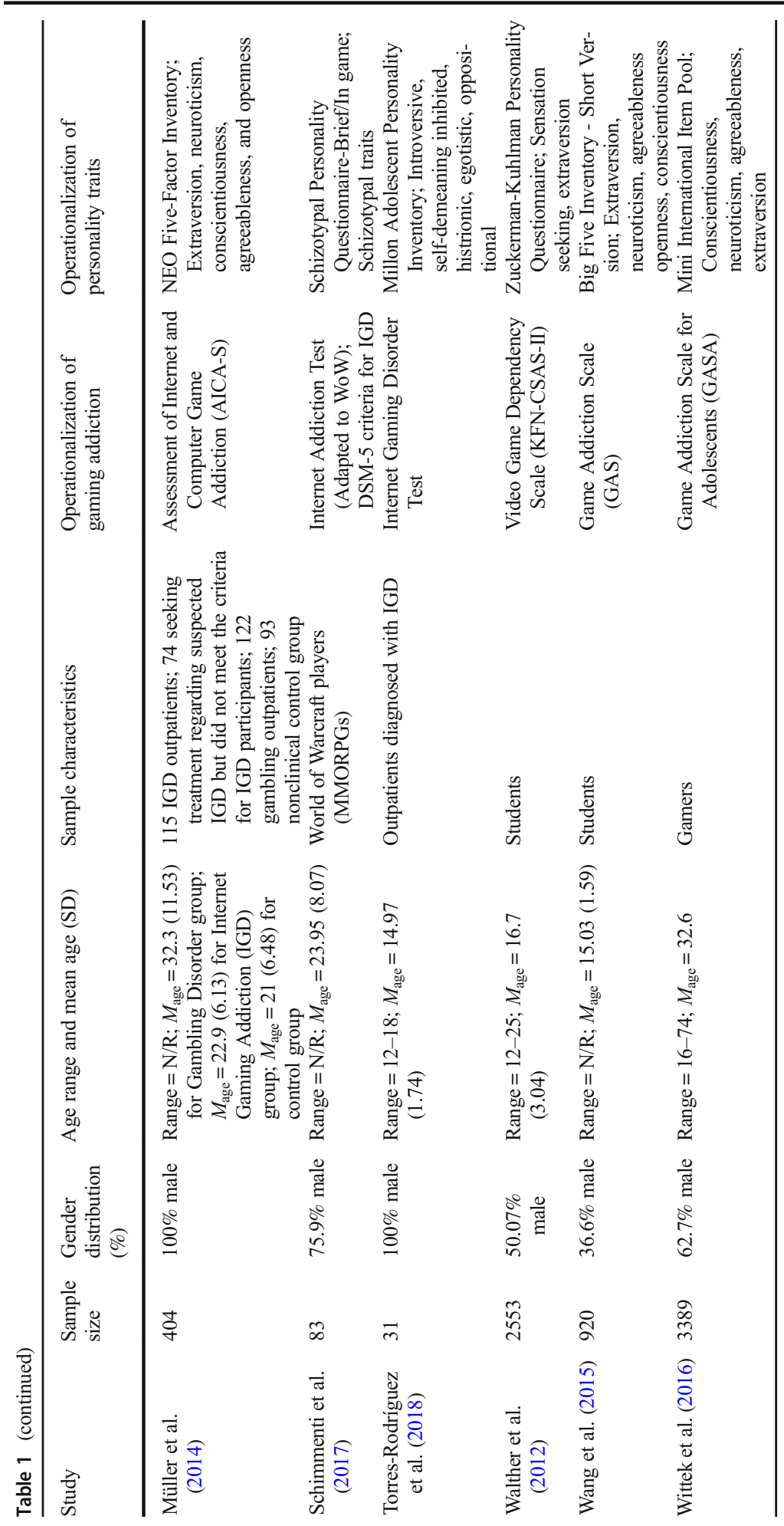


Table 2 Main findings, study limitations, and risk of biases in the studies reviewed $(N=21)$

\begin{tabular}{lll}
\hline Study & Main findings & Study limitations \\
\hline $\begin{array}{c}\text { Borzikowsky and } \\
\text { Bernhardt } \\
(2018)\end{array}$ & $\begin{array}{c}\text { Gaming addiction was } \\
\text { negatively correlated with } \\
\text { grit. Grit predicted } \\
\text { gaming addiction. }\end{array}$ & $\begin{array}{l}\text { Self-selected sample; limited } \\
\text { generalizability because } \\
\text { the data were collected } \\
\text { from only MMOGs } \\
\text { players }\end{array}$ \\
& $\begin{array}{l}\text { Gaming addiction was } \\
\text { negatively correlated with et al. (2016) } \\
\text { extraversion and } \\
\text { conscientiousness }\end{array}$ & $\begin{array}{l}\text { Measurement of gaming } \\
\text { addiction based on } \\
\text { substance related } \\
\text { addiction criteria; the vast } \\
\end{array}$ \\
& & majority of sample were \\
& male
\end{tabular}

Risk of biases

$\begin{array}{cl}\text { Charlton and } & \text { Gaming addiction was } \\ \text { Danforth (2010) } & \text { positively correlated with } \\ & \text { negative valence and } \\ & \text { neuroticism; negatively } \\ \text { correlated with } & \text { extraversion and } \\ & \text { agreeableness. In } \\ & \text { addition, negative valence } \\ & \text { and neuroticism predicted } \\ & \text { gaming addiction }\end{array}$

Chiu et al. (2004) Sensation seeking was positively correlated with gaming addiction; this factor also predicted IGD

Collins et al. (2012)

Gonzalez-Bueso et al. (2018)

Hu et al. (2017) inhibited, introversive and

\section{Agreeableness was negatively correlated with gaming addiction (or in this case with problematic video gaming)}

\section{Gaming addiction was} positively correlated with egoistic traits, and negatively correlated with histrionic trait

\section{Sensation seeking was} positively correlated with gaming addiction; this factor also predicted gaming addiction. However, when controlling for the effect
Measurement of gaming addiction based on addiction and engagement portions of General Computing Questionnaire (the scale originally adapted from Computer Apathy and Anxiety Scale); the vast majority of samples were male; findings related to MMORPG gamers only

Omissions of participants sociodemographic information; limited representativeness of gamer population due to including a student-only sample

Self-selected sample; limited generalizability due to low sample size for gamers; the findings only related to MMORPG gamers

Measurement of gaming addiction based on gambling disorder diagnostic questionnaire; limited representativeness of addicted gamers due to including only male participants and small sample size

Measurement of gaming addiction based on a generalized Internet addiction scale; lack of female participants and sample heterogeneity
Sampling bias due to nonprobability sampling techniques and lack of inclusion of clinical samples

Sampling bias due to nonprobability sampling techniques and lack of inclusion of a clinical sample; measurement bias due to using a tool that originally based on substance related addiction criteria for assessing IGD

Sampling bias due to nonprobability sampling techniques and lack of inclusion clinical samples; measurement bias due to using modified tool from addiction and engagement portions of general computing questionnaire

Sampling bias due to nonprobability sampling techniques and lack of inclusion of clinical samples

Sampling bias due to nonprobability sampling techniques, self-selected sample, and lack of a clinical sample

Sampling bias due to recruitment of a male-only sample; measurement bias due to using a tool that originally based on gambling addiction criteria for assessing IGD

Sampling bias due to nonprobability sampling techniques, lack of inclusion female and clinical samples; measurement bias due to 
Table 2 (continued)

\begin{tabular}{|c|c|}
\hline Study & Main findings \\
\hline & $\begin{array}{l}\text { of affective associations, } \\
\text { the effect of sensation } \\
\text { seeking on online gaming } \\
\text { addiction was no longer } \\
\text { significant. This means } \\
\text { that the full mediation } \\
\text { effect of affective } \\
\text { associations with online } \\
\text { games on the relationship } \\
\text { between sensation } \\
\text { seeking and online } \\
\text { gaming addiction was } \\
\text { significant }\end{array}$ \\
\hline
\end{tabular}

Kim et al. (2008) Narcissistic personality trait was positively correlated with online game addiction; this factor also predicted gaming addiction

Kircaburun et al. (2018)

Kim et al. (2016)

Narcissism and sadism were positively related with gaming addiction. Also, these traits predicted gaming addiction

Self-selected sample; the vast majority of samples were male; shortcomings of participants' demographic information; measurement of gaming addiction based on Young's Internet addiction scale which has modified criteria for substance dependence and had not been used nor validated before by previous studies

Limited generalizability due to lack of female participants; shortcomings of participants' demographic information

Limited generalizability due to low sample size and lack of female participants positively related with Type D personality traits

Laier et al. (2018) Negative affectivity, detachment, antagonism, disinhibition and psychoticism were positively related with gaming addiction. In addition, negative affectivity, detachment and psychoticism predicted IGD

Lee et al. (2017) Novelty seeking and harm avoidance were positively correlated with gaming addiction

\footnotetext{
Lehenbauer-Baum Gaming addiction was and Fohringer (2015)
}

Measurement of gaming addiction based on Internet addiction scale; limited generalizability due to low sample size

Measurement and operationalization of gaming addiction based on general Internet addiction; lack of female participants

Self-selected sample; the vast majority of samples were male; measurement of gaming addiction based
Risk of biases

using modified tool from Internet addiction

Sampling bias due to nonprobability sampling techniques, self-selected samples, and lack of clinical samples; measurement bias due to using modified tool from Internet addiction

Sampling bias due to nonprobability sampling techniques and lack of clinical samples

Sampling bias due to nonprobability sampling techniques, lack of inclusion of female and clinical samples

Sampling bias due to nonprobability sampling techniques and lack of clinical measurement bias due to assessing gaming addiction with an Internet addiction scale

Sampling bias due to nonprobability sampling techniques, lack of inclusion female; measurement bias due to using modified tool from Internet addiction

Sampling bias due to nonprobability sampling techniques, self-selected samples and lack of 
Table 2 (continued)

\begin{tabular}{|c|c|c|c|}
\hline Study & Main findings & Study limitations & Risk of biases \\
\hline & $\begin{array}{l}\text { agreeableness personality } \\
\text { traits }\end{array}$ & $\begin{array}{l}\text { on addiction and } \\
\text { engagement portions of } \\
\text { General Computing } \\
\text { Questionnaire (the scale } \\
\text { originally adapted from } \\
\text { Computer Apathy and } \\
\text { Anxiety Scale) and had } \\
\text { not been used nor } \\
\text { validated before by } \\
\text { previous studies; findings } \\
\text { related to WoW players } \\
\text { only; lack important } \\
\text { variables which are } \\
\text { difference between } \\
\text { engaged and addicted } \\
\text { players, such as } \\
\text { depression or social } \\
\text { anxiety of control of }\end{array}$ & $\begin{array}{l}\text { clinical samples; mea- } \\
\text { surement bias due to } \\
\text { using modified tool from } \\
\text { addiction and engagement } \\
\text { portions of general com- } \\
\text { puting questionnaire }\end{array}$ \\
\hline Li et al. (2016) & $\begin{array}{l}\text { Neuroticism was positively } \\
\text { correlated with gaming } \\
\text { addiction; this factor also } \\
\text { predicted gaming } \\
\text { addiction. Additionally, } \\
\text { neuroticism moderated } \\
\text { the indirect effect of } \\
\text { stressful life events on } \\
\text { online gaming addiction } \\
\text { via avoidant coping } \\
\text { styles. However, there } \\
\text { wasn't any significant } \\
\text { relationship between } \\
\text { extraversion and gaming } \\
\text { addiction }\end{array}$ & $\begin{array}{l}\text { Limited representativeness } \\
\text { of gamer population due } \\
\text { to including a } \\
\text { student-only sample }\end{array}$ & $\begin{array}{l}\text { Sampling bias due to } \\
\text { nonprobability sampling } \\
\text { techniques and lack of a } \\
\text { clinical sample }\end{array}$ \\
\hline $\begin{array}{l}\text { Mehroof and } \\
\text { Griffiths (2010) }\end{array}$ & $\begin{array}{l}\text { Online gaming addiction was } \\
\text { positively correlated with } \\
\text { neuroticism and sensation } \\
\text { seeking. In addition, traits } \\
\text { of neuroticism and } \\
\text { sensation seeking } \\
\text { predicted gaming } \\
\text { addiction }\end{array}$ & $\begin{array}{l}\text { Limited generalizability due } \\
\text { to low sample size and } \\
\text { including a student-only } \\
\text { sample }\end{array}$ & $\begin{array}{l}\text { Sampling bias due to } \\
\text { nonprobability sampling } \\
\text { techniques and lack of a } \\
\text { clinical sample }\end{array}$ \\
\hline $\begin{array}{l}\text { Müller et al. } \\
\text { (2014) }\end{array}$ & $\begin{array}{l}\text { Gaming addiction positively } \\
\text { correlated with } \\
\text { neuroticism and } \\
\text { negatively correlated with } \\
\text { extraversion, } \\
\text { agreeableness, } \\
\text { conscientiousness and } \\
\text { openness to experience } \\
\text { domain. Additionally, } \\
\text { neuroticism, extraversion, } \\
\text { openness and } \\
\text { conscientiousness } \\
\text { contributed significantly } \\
\text { to explaining the gaming } \\
\text { addiction }\end{array}$ & Lack of female participants & $\begin{array}{l}\text { Sampling bias due to } \\
\text { recruitment of a } \\
\text { male-only sample }\end{array}$ \\
\hline
\end{tabular}


Table 2 (continued)

\begin{tabular}{|c|c|c|c|}
\hline Study & Main findings & Study limitations & Risk of biases \\
\hline $\begin{array}{l}\text { Schimmenti et al. } \\
\text { (2017) }\end{array}$ & $\begin{array}{l}\text { Schizotypal traits were } \\
\text { positively correlated with } \\
\text { gaming addiction; this } \\
\text { factor also predicted } \\
\text { gaming addiction. In } \\
\text { addition, participants } \\
\text { reported that their } \\
\text { schizotypal traits } \\
\text { (disorganized and } \\
\text { interpersonal) reduced } \\
\text { when they involved in } \\
\text { gaming due to thinking } \\
\text { about themselves in the } \\
\text { virtual world }\end{array}$ & $\begin{array}{l}\text { Self-selected samples; low } \\
\text { sample size; the vast } \\
\text { majority of samples were } \\
\text { male; gaming addiction } \\
\text { group consisting solely of } \\
\text { WoW gamers so findings } \\
\text { related to them only; } \\
\text { shortcomings of } \\
\text { participants' } \\
\text { sociodemographic } \\
\text { information; one of the } \\
\text { measurements for } \\
\text { assessing gaming } \\
\text { addiction based on } \\
\text { generalized Internet } \\
\text { addiction scale and the } \\
\text { other one had not been } \\
\text { used nor validated before } \\
\text { by previous studies }\end{array}$ & $\begin{array}{l}\text { Sampling bias due to } \\
\text { nonprobability sampling } \\
\text { techniques, self-selected } \\
\text { samples and lack of clini- } \\
\text { cal samples; measurement } \\
\text { bias due to using modified } \\
\text { tool from Internet addic- } \\
\text { tion }\end{array}$ \\
\hline $\begin{array}{l}\text { Torres-Rodríguez } \\
\text { et al. (2018) }\end{array}$ & $\begin{array}{l}\text { Gaming addiction was } \\
\text { negatively related with } \\
\text { oppositional and } \\
\text { self-demeaning traits }\end{array}$ & $\begin{array}{l}\text { Limited generalizability due } \\
\text { to small sample size and } \\
\text { including a male-only } \\
\text { sample; there was no } \\
\text { control group to compare } \\
\text { results }\end{array}$ & $\begin{array}{l}\text { Sampling bias due to } \\
\text { recruitment of a } \\
\text { male-only sample }\end{array}$ \\
\hline $\begin{array}{l}\text { Walther et al. } \\
\text { (2012) }\end{array}$ & $\begin{array}{l}\text { There was no significant } \\
\text { relationship between } \\
\text { gaming addiction and the } \\
\text { traits of extraversion and } \\
\text { sensation seeking }\end{array}$ & $\begin{array}{l}\text { Measurement of gaming } \\
\text { addiction based on } \\
\text { non-substance-related ad- } \\
\text { diction according to ICD } \\
10 \text { criteria; measurement of } \\
\text { the personality trait was } \\
\text { strongly reduced in size; } \\
\text { limited representativeness } \\
\text { of gamer population due to } \\
\text { including a student-only } \\
\text { sample }\end{array}$ & $\begin{array}{l}\text { Sampling bias due to } \\
\text { nonprobability sampling } \\
\text { techniques and lack of } \\
\text { clinical samples; } \\
\text { measurement bias due to } \\
\text { using a tool that originally } \\
\text { based on non-substance } \\
\text { related addiction accord- } \\
\text { ing to ICD criteria for } \\
\text { assessing IGD and per- } \\
\text { sonality measurement that } \\
\text { were strongly reduced in } \\
\text { size }\end{array}$ \\
\hline Wang et al. (2015) & $\begin{array}{l}\text { Gaming addiction was } \\
\text { negatively correlated with } \\
\text { conscientiousness and } \\
\text { openness to experience. } \\
\text { Additionally, these factors } \\
\text { predicted gaming } \\
\text { addiction }\end{array}$ & $\begin{array}{l}\text { Shortcomings of } \\
\text { participants' } \\
\text { sociodemographic } \\
\text { information; limited } \\
\text { representativeness of } \\
\text { gamer population due to } \\
\text { including only student } \\
\text { sample }\end{array}$ & $\begin{array}{l}\text { Sampling bias due to } \\
\text { nonprobability sampling } \\
\text { techniques and lack of a } \\
\text { clinical sample }\end{array}$ \\
\hline Wittek et al. (2016) & $\begin{array}{l}\text { Game addiction was } \\
\text { negatively associated with } \\
\text { conscientiousness and } \\
\text { positively associated with } \\
\text { neuroticism. Additionally, } \\
\text { these factors predicted } \\
\text { gaming addition }\end{array}$ & $\begin{array}{l}\text { The vast majority of the } \\
\text { sample were male }\end{array}$ & $\begin{array}{l}\text { Sampling bias due to lack of } \\
\text { a clinical sample. }\end{array}$ \\
\hline
\end{tabular}




\section{Operationalization of Internet Gaming Disorder}

Operationalization of a variable includes defining how a variable is measured objectively (Dantzker and Hunter 2011). Three of the reviewed studies used modified tools based on generalized Internet addiction criteria such as the Online Gaming Addiction Scale, Online Game Addiction Scale and Internet Addiction Test-Adapted to WoW (Hu et al. 2017; Kim et al. 2008; Schimmenti et al. 2017), two studies adopted the Addiction-Engagement Scale and World of Warcraft Questionnaire which are modified tools based on addiction and engagement portions of General Computing Questionnaire (this scale originally adapted from Computer Apathy and Anxiety Scale) (Charlton and Danforth 2010; LehenbauerBaum and Fohringer 2015), one study adopted the Video Game Dependency Scale which is a modified tool based on non-substance related addiction according to ICD 10 criteria (Walther et al. 2012), one study used the Assessment of Internet and Computer Game Addiction which is a modified tool based on substance related addiction criteria (Braun et al. 2016), one study used the Diagnostic Questionnaires for Video Games, Mobile Phones or Internet Addiction which is modified tool based on gambling addiction criteria (Gonzalez-Bueso et al. 2018), and two studies used the Internet Addiction Test and Internet Addiction Scale (Laier et al. 2018; Chiu et al. 2004). All of the remaining studies assessed IGD based on gaming addiction/dependency criteria and used scales specifically designed to assess problematic gaming.

\section{Personality Traits Associated with Internet Gaming Disorder}

A number of studies examined the relationship between the Big Five personality traits and IGD, but the findings were somewhat conflicting. While some studies reported that there was a positive association between IGD and conscientiousness (Lehenbauer-Baum and Fohringer 2015), agreeableness (Lehenbauer-Baum and Fohringer 2015), and neuroticism (Charlton and Danforth 2010; Li et al. 2016; Mehroof and Griffiths 2010; Müller et al. 2014; Wittek et al. 2016), others indicated that IGD was negatively correlated with conscientiousness (Braun et al. 2016; Müller et al. 2014; Wang et al. 2015; Wittek et al. 2016), extraversion (Braun et al. 2016; Charlton and Danforth 2010; Müller et al. 2014), agreeableness (Charlton and Danforth 2010; Collins et al. 2012; Müller et al. 2014), and openness to experience (Müller et al. 2014; Wang et al. 2015). In addition to these, other studies found no relationship between IGD and conscientiousness (Collins et al. 2012), neuroticism (Braun et al. 2016; Collins et al. 2012; LehenbauerBaum and Fohringer 2015; Wang et al. 2015), extraversion (Collins et al. 2012; Lehenbauer-Baum and Fohringer 2015; Li et al. 2016; Walther et al. 2012; Wang et al. 2015; Wittek et al. 2016), agreeableness (Braun et al. 2016; Wang et al. 2015; Wittek et al. 2016), and openness to experience (Braun et al. 2016; Collins et al. 2012; Lehenbauer-Baum and Fohringer 2015).

When the results of regression analysis related with the Big Five personality traits were evaluated, low scores on conscientiousness (Müller et al. 2014; Wang et al. 2015; Wittek et al. 2016), extraversion (Müller et al. 2014), openness to experience (Müller et al. 2014; Wang et al. 2015), and high score on neuroticism (Charlton and Danforth 2010; Li et al. 2016; Mehroof and Griffiths 2010; Müller et al. 2014; Wittek et al. 2016) predicted gaming addiction. In addition, Li et al. (2016) reported that neuroticism moderated the indirect effect of stressful life events on online gaming addiction via avoidant coping styles. 
In relation to the association between sensation seeking and IGD, more consistent results were reported with either a positive relationship between IGD and sensation seeking (Chiu et al. 2004; Hu et al. 2017; Mehroof and Griffiths 2010) or no relationship (Collins et al. 2012; Walther et al. 2012). In addition, the regression analysis demonstrated that high sensation seeking predicted IGD (Chiu et al. 2004; Hu et al. 2017; Mehroof and Griffiths 2010). Hu et al. (2017) also noted that when controlling for the effect of affective associations, the effect of sensation seeking on online gaming addiction was no longer significant. This means that affective associations had a full mediation effect on the relationship between sensation seeking and online gaming addiction.

Some studies reported that IGD was positively correlated with negative valence (i.e., being demanding, needy, and eager to impress) (Charlton and Danforth 2010), schizotypal traits (Schimmenti et al. 2017), narcissism (Gonzalez-Bueso et al. 2018; Kircaburun et al. 2018; Kim et al. 2008), psychoticism, disinhibition (i.e., being irresponsible, impulsive, and a high risk taker), antagonism (i.e., being hostile, manipulative, deceitful, and callous), detachment (i.e., having restricted affectivity, anhedonia, suspiciousness, and intimacy avoidance), negative affectivity (i.e., being emotionally labile, anxious, and submissive) (Laier et al. 2018), sadism (i.e., demonstrating cruel and deviant behaviors and inflicting intentional pain on others to feel powerful) (Kircaburun et al. 2018), inhibition (which refers to an avoidant personality disorder's pattern at DSM-III-R), introversive (which refers to a schizoid personality disorder's pattern at DSM-III-R), and Type D personality traits (which is defined as a combination of negative affectivity and social inhibition) (Kim et al. 2016). The same studies also reported that IGD was predicted by negative valence (Charlton and Danforth 2010), schizotypal traits (Schimmenti et al. 2017), narcissism (Kurcaburun et al. 2018; Kim et al. 2008), sadism (Kurcaburun et al. 2018), grit (Borzikowsky and Bernhardt 2018), negative affectivity, detachment, and psychoticism (Laier et al. 2018). Others reported that IGD was negatively correlated with histrionic trait (Gonzalez-Bueso et al. 2018), grit (i.e., ability to be persistent in pursuit of long-term goals) (Borzikowsky and Bernhardt 2018), and oppositional and self-demeaning traits (which refer to self-defeating personality disorder patterns at DSM-II-R) (Torres-Rodríguez et al. 2018). Finally, one investigated temperament and character components of personality, and reported that those with IGD had higher novelty seeking and harm avoidance scores than the healthy individuals (Lee et al. 2017).

\section{Risk of Bias in Individual Studies}

With regard to the process of assessing risk of bias in each study, sampling bias and measurement bias were assessed. On these biases - excluding one study (Torres-Rodríguez et al. 2018) - all of the remaining studies were rated as having risk of sampling bias due to (i) adopting nonprobability sampling techniques and/or self-selected samples, (ii) collecting data from male-only samples, and/or (iii) omission of clinical samples. Additionally, measurement bias was rated as high risk in some of the reviewed studies due to using modified tools which based on Internet addiction criteria (Hu et al. 2017; Kim et al. 2008; Laier et al. 2018; Chiu et al. 2004; Schimmenti et al. 2017), non-substance addiction criteria (Gonzalez-Bueso et al. 2018; Walther et al. 2012), substance-related addiction criteria (Braun et al. 2016), or anxiety related with general computing (Charlton and Danforth 2010; Lehenbauer-Baum and Fohringer 2015). 


\section{Methodological Features of Studies}

With regard to key methodological features of studies, all studies reviewed were empirical and quantitative nature. The majority of the studies employed a cross-sectional design (Braun et al. 2016; Charlton and Danforth 2010; Chiu et al. 2004; Collins et al. 2012; Gonzalez-Bueso et al. 2018; Kim et al. 2008; Kim et al. 2016; Lee et al. 2017; Lehenbauer-Baum and Fohringer 2015; Mehroof and Griffiths 2010; Müller et al. 2014; Schimmenti et al. 2017; TorresRodríguez et al. 2018; Walther et al. 2012; Wang et al. 2015; Wittek et al. 2016), and five studies adopted a mixed-methods design (Borzikowsky and Bernhardt 2018; Hu et al. 2017; Kurcaburun et al. 2018; Laier et al. 2018; Li et al. 2016). Excluding three studies that combined both self-report questionnaires and clinical interviews (Gonzalez-Bueso et al. 2018; Müller et al. 2014; Torres-Rodríguez et al. 2018), the remaining 18 studies used self-report questionnaires to collect data. Moreover, while ten studies employed online surveys with self-report measures for assessing IGD (Borzikowsky and Bernhardt 2018; Braun et al. 2016; Charlton and Danforth 2010; Collins et al. 2012; Kırcaburun et al. 2018; Kim et al. 2008; Laier et al. 2018; Lehenbauer-Baum and Fohringer 2015; Mehroof and Griffiths 2010; Schimmenti et al. 2017), and 11 studies used paper-and-pencil survey methods (Chiu et al. 2004; GonzalezBueso et al. 2018; Hu et al. 2017; Kim et al. 2016; Lee et al. 2017, Li et al. 2016; Müller et al. 2014; Torres-Rodríguez et al. 2018; Walther et al. 2012; Wang et al. 2015; Wittek et al. 2016).

As to the sampling methods adopted, only one study used a probability-sampling method to identify samples (Wittek et al. 2016). Apart from one study that combined both convenience and snowball sampling methods (Kim et al. 2016), all the reviewed studies used convenience sampling or self-selected sampling to recruit participants.

Several types of limitations were identified across all 21 studies (see Table 2), and they can be grouped within three types: (a) sampling problems, (b) measurement problems, and (c) lack of longitudinal studies (i.e., all studies were cross-sectional). Sampling problems included (i) widely employing non-probability sampling methods, (ii) sampling homogeneity due to including male-only samples within some studies, (iii) the omission of clinical samples within the majority of studies, and (iv) low sample sizes. Measurement problems included employing modified measurements that originally designed for evaluating generalized Internet addiction and not validated by previous studies.

\section{Discussion}

The present review identified peer-reviewed published examining the association of personality traits with Internet Gaming Disorder. The present review also extracted data from the reviewed studies including: (i) country in which data were collected, (ii) main characteristics of participants, (iii) operationalization of IGD, (iv) personality traits related with IGD, (v) risk of bias in individual studies, and (vi) methodological features of studies.

In terms of geographic dispersion, one-third of the studies $(n=7)$ were conducted in the Asian context, and the others were conducted either in European countries and/or the USA. As for the participants involved in the studies reviewed, similar patterns appeared across the studies. More specifically, studies tended to comprise: (i) more male participants than female, (ii) adult samples rather than adolescents, (iii) student samples rather than clinical samples and/or individuals from the more general population, and (iv) 
MMORPG players rather than non-MMORPG players. Based on these observations, future studies examining personality traits and IGD should employ other samples (children and adolescents, females, clinical samples, and players from other gaming genres) to enhance external validity.

With regard to the operationalization of IGD, while half of the reviewed studies used gaming addiction criteria, the others adopted a modified measurement that was based on Internet addiction criteria, and substance or non-substance related addiction criteria. The use of such scales severely restricts the reliability of the cross-cultural studies (Pontes and Griffiths 2014). Therefore, validated instruments specifically designed to assess IGD should be employed and tested in different settings to improve cross-cultural reliability (Griffiths et al. 2014).

The main objective of the present review was to identify studies examining the relationship between personality traits and IGD. Results demonstrated that 24 distinct personality traits had been examined in relation to IGD and that some of these traits were demonstrated as risk factors for gaming addiction (although not always in the same direction).

A negative association (Braun et al. 2016; Charlton and Danforth 2010; Müller et al. 2014) or no relationship (Collins et al. 2012; Lehenbauer-Baum and Fohringer 2015; Li et al. 2016; Walther et al. 2012; Wang et al. 2015; Wittek et al. 2016) between extraversion and IGD was reported. The extraversion trait has been identified as social interaction's intensity and selfconfidence level of individuals (McCrae and Costa 1987). Extraverted people have satisfying interpersonal relationships and social support in their real lives (McCrae and Costa 1997). Therefore, this would mean that such individuals do not need to use games to fulfill their desire of being part of a social network (Müller et al. 2014). However, introverted gamers might get involved in the social networks of MMORPGs to compensate for low life satisfaction, low self-esteem, and poor face-to-face social skills (Müller et al. 2014). This supports the social compensation principle of "the poor get richer" (Barker 2009). Concordantly, gaming addiction was related to higher introversive traits (which refers to a schizoid personality disorder's pattern in DSM-III-R) and inhibition traits (which refers to an avoidant personality disorder's pattern in DSM-III-R), and lower histrionic traits (which refers to histrionic personality disorder in DSM-III-R) (Gonzalez-Bueso et al. 2018). Alternatively, extraverted people might also participate in the virtual games environment to improve social enhancement and supports "the rich get richer" principle (Barker 2009). In addition, some introverted people may not be able to maintain being involved in some games because the games require friendly and cooperative attitude (Y1lmaz 2015).

Mixed results were found concerning the relationship between conscientiousness and IGD. In addition, according to regression analyses, low conscientiousness predicted IGD (Müller et al. 2014; Wang et al. 2015; Wittek et al. 2016). People with low conscientiousness are unable to pursue to personal aims, poorly organize their day-to-day lives, and lack structure in their lives. They are more likely to ignore their responsibilities of everyday life and do not think through the consequences of engaging in activities excessively. Therefore, they are more likely to lose themselves in virtual game environments (Müller et al. 2014). Along similar lines, the review identified grit as a protective factor against gaming addiction (Borzikowsky and Bernhardt 2018) and disinhibition as a predictor factor for gaming addiction (Laier et al. 2018). The "grit" personality trait is described as being persistent in pursuit of long-term goals despite obstacles (Schmidt et al. 2017), and the disinhibition trait is associated with irresponsibility, impulsivity, and distractibility (Trull 2012). While higher grit (Eskreis-Winkler et al. 2014) and lower disinhibition trait scores serve as a significant predictor factor for achievement, these patterns were identified as a protective factor against gaming addiction. 
Alternatively, individuals with high conscientiousness and high self-efficacy deal with complexity in games and have strong motivations to improve their skills and thus to keep playing games (Klimmt and Hartmann 2006). However, it is thought that other comorbid factors may have an effect on these contradictory findings. Consequently, further study is needed concerning the possible confounding factors in this association.

The relationship between neuroticism was more consistent with either a positive relationship between IGD and neuroticism (Charlton and Danforth 2010; Li et al. 2016; Mehroof and Griffiths 2010; Müller et al. 2014; Wittek et al. 2016), or no relationship (Braun et al. 2016; Collins et al. 2012; Lehenbauer-Baum and Fohringer 2015; Wang et al. 2015). No studies found a relationship between low neuroticism and IGD. Neurotic people are emotionally unstable and unconfident. Overall, they have an anxious predisposition and undeveloped self-awareness (Costa and McCrae 1992), perceive situations more stressfully, and have more troubled relationships (Zhou et al. 2017). Consequently, they might use gaming as a way of preventing or inhibiting negative feelings (Mehroof and Griffiths 2010) and escaping their problems (Wittek et al. 2016). Additionally, neuroticism is related with impulsiveness (Costa and McCrae 1992). This might also contribute to being addicted to video games (Wittek et al. 2016). Here, gaming may end up being a dysfunctional coping strategy (Müller et al. 2014). Alternatively, a possible reason for finding no relationship between neuroticism and IGD is that neurotic people might not be able to concentrate as well in-game due to loss of emotional balance (Wang et al. 2015). The types of games played might also have important role in the relationship. Chory and Goodboy (2011) reported that neuroticism scores were higher among violent video game users than non-violent video game users.

Mixed results were also found concerning the relationship between agreeableness and IGD. Agreeable people do not come into conflict easily and keep away from competition. They have a tolerant and highly forgiving personality (McCrae and Costa 1987). In contrast, low-level agreeableness is related with behaving aggressively and hostile (Costa and McCrae 1992). That is, individuals with low levels of agreeableness tend to experience unsatisfying relationships and have more interpersonal conflicts in their real lives (Ozer and Benet-Martinez 2006). In a similar manner, the personality traits antagonism (which is associated with hostility, manipulativeness, deceitfulness, and callousness) and sadism (which is described as behaving cruelly, humiliating and inflicting intentional pain on others to feel powerful) critically caused interpersonal conflicts and positively related with IGD (Laier et al. 2018; Kurcaburun et al. 2018). Therefore, gamers with lower agreeableness, higher sadism, and antagonism might prefer to form social contacts in virtual settings due to not requiring close social boundaries (Müller et al. 2014) and/or to escape into a world where they can hurt others and exercise their fantasies of hurting without any serious consequences (Kurcaburun et al. 2018). This make them feel superior and they lose themselves in the game over time (Müller et al. 2014). Alternatively, some video games require a good communication with the other gamers to gain a tactical advantage (Y1lmaz 2015), and others require the gamer to enact violent behaviors. Chory and Goodboy (2011) demonstrated that low agreeableness especially associated with playing violent games. Consequently, the association between agreeableness and IGD might be valid for specific types of video games (Wittek et al. 2016).

Findings of the studies reviewed demonstrated a negative association (Müller et al. 2014; Wang et al. 2015) or no relationship (Braun et al. 2016; Collins et al. 2012; Lehenbauer-Baum and Fohringer 2015) between openness to experience and IGD. People with high openness to experience scores are independent, intellectual, highly imaginative, and open-minded. They have high curiosity and interest levels (Costa and McCrae 1992). From this point of view, such people 
might be in search of both real and virtual life settings to fulfill their curiosity and interest (Kayiş et al. 2016). One possible reason for significant association between low openness and IGD is that they prefer to stick with their gaming rather than seeking out new activities, and so this type of personality trait might be more likely help to maintain their IGD rather than be a factor in its development (Müller et al. 2014). Additionally, openness is related to features of intelligence, and also a low level of emotional intelligence is associated with IGD (Parker et al. 2008); so intelligence might be an important factor between low openness and IGD (Müller et al. 2014). Alternatively, as mentioned above, individuals with higher openness scores might also use virtual life settings to satisfy their needs via variety of games' opportunities. Consequently, further research is needed concerning the genre of games in relation to this association.

In relation to the association between sensation seeking and IGD, more consistent results were reported with either a positive relationship between IGD and sensation seeking (Chiu et al. 2004; Hu et al. 2017; Mehroof and Griffiths 2010) or no relationship (Collins et al. 2012; Walther et al. 2012). Individuals higher in sensation seeking are interested in activities rich in adventure, and ever changeable experiences. They always have an internal motivation to pursue new environments and challenges. More specifically, sensation seeking is related to a dislike of being in a controlled, tranquil life, and they often oppose traditional social values (Farley 1986). They have an impulsive, ambitious, and challenging personality, and this may correspond well in many game scenarios. In other words, the possible reason for the positive relationship between sensation seeking and IGD is that high sensation seekers satisfy their needs of adventure, novelty, and challenge via the playing of video games (Chiu et al. 2004). Alternatively, Buchman and Funk (1996) considered that violent games have the stimulation to attract the gamers with high sensation seeking. From this point of view, the result of no association between sensation seeking and IGD may have been due to the inclusion of nonviolent games in research. This association needs to be investigated in further research. In addition, this result was explained with the measurement tool for assessing sensation seeking which was strongly reduced in size (Walther et al. 2012).

In respect to narcissism (which refers to "egoistic" trait in the Millon Adolescent Clinical Inventory), the trait positively predicted IGD (Gonzalez-Bueso et al. 2018; Kircaburun et al. 2018; Kim et al. 2008). Consistent with the findings, negative relationships between IGD and some components of self-defeating personality disorder such as "oppositional" and "selfdemeaning" traits were reported. Individuals higher in narcissism attach importance to sense of self-importance and success, and they dote upon others' attention and admiration excessively (Kim et al. 2008). Some kinds of game such as MMORPGs might attract them due to their achievement-based systems. More specifically, an avatar upgrades its skills and gains strength with valuables and weapons via experience points. A narcissistic individual can gain others' attention and admiration in this type of social environment. Also, this setting might cause them to feel more confident and to find admiring audience (Kim et al. 2008).

Higher schizotypal personality trait also predicted IGD. More specifically, high levels of schizotypal personality traits are positively related with immersion motivation for gaming and negatively related with social motivations (Schimmenti et al. 2017). Schizotypal personalities are defined as individuals suffering in their social relationships. For instance, they dislike being in close relationships due to reduced skills and their odd thinking. Their increased social anxiety might diminish in a virtual environment that do not require close relationships or sharing their emotions, and where communication is mediated by the avatar. It also may be easier for them to deal with the mechanical dimension of a game rather than its social side. Furthermore, schizotypal individuals might experience bizarre beliefs, abnormal perceptual 
processes, and improper affects and behaviors. Similarly, psychoticism (which is associated with unusual beliefs and experiences), eccentricity, and perceptual dysregulation, positively predicted gaming addiction, and avoidance expectancies mediated this relationship (Laier et al. 2018). These findings might suggest that gamers share their beliefs and pursue odd thinking without fear of judgment by identifying themselves with their avatar (Schimmenti et al. 2017). Sioni et al. (2017) noted that higher social anxiety promotes stronger avatar identification, which in turn compounds IGD symptoms. Consequently, further study is needed in which these personality traits are investigated as a moderator factor in determining the degree to which individuals identify with their avatars.

Negative valence, detachment, negative affectivity, and Type D personality were both found to be positively associated with IGD. These dimensions are related with undesirable behaviors. For instance, negative valence is defined as being demanding, needy, and eager to impress (Charlton and Danforth 2010); negative affectivity is associated with emotional lability and defined as being anxious, submissive, depressive, and suspicious (Trull 2012). Similarly, detachment is described as restricted affectivity, anhedonia, withdrawal, and intimacy avoidance (Trull 2012). Type D personality (distressed personality) is defined as a combination of being prone to feel negative effects and restraining the expression of emotions, and interpreting the world and oneself negatively (Denollet 2005). Individuals with these personality traits usually have low selfesteem and use some types of video game (e.g., MMORPGs) to fulfill their needs of interactions with others and social reinforcement (Charlton and Danforth 2010; Laier et al. 2018), and to escape their feelings of inadequacy (Armstrong et al. 2000). This tangible explanation lends some credence to the possibility that game motivations are also based on the results of contextual and psychological factors, as with motivations more generally (Ryan et al. 2006).

Finally, novelty seeking and harm avoidance traits were found to be positively associated with IGD (Lee et al. 2017). While novelty seeking is associated with getting cravings due to the effect of dopamine system, and thus being in search of new experiences, harm avoidance is related with high level of anxiety and shyness (Cloninger et al. 1994; cited in Lee et al. 2017). As explained above, it is considered normal for individuals with higher novelty seeking and harm avoidance traits to be prone to gaming addiction because of the personality traits' relatedness with seeking new experiences and high level of anxiety, respectively. The findings from the reviewed studies have the potential to enrich extant theoretical models and treatment of IGD.

With regard to risk of bias in individual studies - excluding one study (Torres-Rodríguez et al. 2018) - a high risk of sampling bias was found in all of the remaining studies, and closely followed by measurement bias. Additionally, most of the studies employed cross-sectional designs, and only five studies adopted a mixed-method design (Borzikowsky and Bernhardt 2018; Hu et al. 2017; Kırcaburun et al. 2018; Laier et al. 2018; Li et al. 2016). Apart from three studies that combined both self-report questionnaires and clinical interviews (Gonzalez-Bueso et al. 2018; Müller et al. 2014; Torres-Rodríguez et al. 2018), all of the studies adopted selfreport surveys to collate data. Apart from one study that used a probability-sampling method (Wittek et al. 2016), all studies adopted a nonprobability-sampling method such as convenience or self-selected sampling methods to recruit participants. Taken together, all of these findings arguably restrict the generalizability of the results of the reviewed studies.

Consequently, future studies should utilize longitudinal and experimental designs, probability-sampling methods, and clinical interviews. Furthermore, ten studies used online surveys. Using online surveys is increasing in this field of research. Such methodologies increase self-disclosure (Joinson 2001) and disinhibition (Suler 2004), while decreasing social desirability and research-related costs (Griffiths 2010). 
Finally, as noted above, several types of limitations identified can be broadly grouped within three types: (i) sampling problems, (ii) measurement problems, and (iii) lack of longitudinal studies (i.e., all studies were cross-sectional). Attention should be paid to these in order to improve the quality of studies published in the IGD field.

\section{Limitations}

Despite the comprehensive search across databases, some related papers might be missed due to including only studies published on English and Turkish, selected search terms, and database limitations. Additionally, important data might be contained in non-peer-reviewed studies, unpublished theses, and dissertation studies.

\section{Conclusions}

As a concluding note, the findings obtained in the present review make evident the usefulness of examining the role of personality traits in the etiology of IGD. According to the findings, personality traits should be continued to be researched. Future research might enhance the understanding of IGD by providing (i) findings on gender differences regarding risk factors underpinning IGD, (ii) cross-cultural data concerning IGD, and (iii) data concerning specific game genres, playing motivations, and/or the degree of player-avatar identification as a moderator or mediator factor in the association between personality traits and IGD.

Funding information This study received no funding.

\section{Compliance with Ethical Standards}

Conflict of Interest The authors declare that they do not have any interests that could constitute a real, potential, or apparent conflict of interest with respect to their involvement in the publication. The authors also declare that they do not have any financial or other relations (e.g., directorship, consultancy, or speaker fee) with companies, trade associations, unions, or groups (including civic associations and public interest groups) that may gain or lose financially from the results or conclusions in the study.

Ethical Approval All procedures performed in this study involving human participants were in accordance with the ethical standards of University's Research Ethics Board and with the 1975 Helsinki Declaration.

Informed Consent Informed consent was obtained from all participants.

Open Access This article is distributed under the terms of the Creative Commons Attribution 4.0 International License (http://creativecommons.org/licenses/by/4.0/), which permits unrestricted use, distribution, and reproduction in any medium, provided you give appropriate credit to the original author(s) and the source, provide a link to the Creative Commons license, and indicate if changes were made.

\section{References}

American Psychiatric Association. (2013). Diagnostic and statistical manual of mental disorders (5th ed.). Arlington, VA: American Psychiatric Publishing.

Armstrong, L., Phillips, J. G., \& Saling, L. L. (2000). Potential determinants of heavier Internet usage. International Journal of Human-Computer Studies, 53(4), 537-550. 
Barker, V. (2009). Older adolescents' motivations for social network site use: The influence of gender, group identity, and collective self-esteem. Cyberpsychology \& Behavior, 12(2), 209-213.

Borzikowsky, C., \& Bernhardt, F. (2018). Lost in virtual gaming worlds: Grit and its prognostic value for online game addiction. The American Journal on Addictions, 27(5), 433-438.

Braun, B., Stopfer, J. M., Müller, K. W., Beutel, M. E., \& Egloff, B. (2016). Personality and video gaming: Comparing regular gamers, non-gamers, and gaming addicts and differentiating between game genres. Computers in Human Behavior, 55, 406-412.

Buchman, D. D., \& Funk, J. B. (1996). Video and computer games in the 90s: Children's time commitment \& game preference. Children Today, 24, 12-15.

Charlton, J. P., \& Danforth, I. D. (2010). Validating the distinction between computer addiction and engagement: Online game playing and personality. Behaviour \& Information Technology, 29(6), 601-613.

Chiu, S. I., Lee, J. Z., \& Huang, D. H. (2004). Video game addiction in children and teenagers in Taiwan. CyberPsychology \& Behaviour, 7(5), 571-581.

Chory, R., \& Goodboy, A. K. (2011). Is basic personality related to violent and non-violent video game play and preferences? Cyberpsychology, Behavior and Social Networking, 14(4), 191-198.

Cloninger, C. R., Przybeck, T. R., Svrakic, D. M., \& Wetzel, R. D. (1994). The Temperament and Character Inventory (TCI): A guide to its development and use. St. Louis, MO: Center for Psychobiology of Personality.

Collins, E., Freeman, J., \& Chamarro-Premuzic, T. (2012). Personality traits associated with problematic and non-problematic massively multiplayer online role playing game use. Personality and Individual Differences, 52, 133-138.

Costa, P. T., \& McCrae, R. R. (1992). Four ways five factors are basic. Personality and Individual Differences, 13(6), 653-665.

Dantzker, M. L., \& Hunter, R. D. (2011). Research methods for criminology and criminal justice (3rd edition). Sudbury, MA: Jones \& Bartlett Learning.

Demetrovics, Z., Urbán, R., Nagygyörgy, K., Farkas, J., Griffiths, M. D., Pápay, O., Kökönyei, G., Felvinczi, K., \& Oláh, A. (2012). The development of the problematic online gaming questionnaire (POGQ). PLoS One, $7(5), \mathrm{e} 36417$.

Denollet, J. (2005). DS14: Standard assessment of negative affectivity, social inhibition, and type D personality. Psychosomatic Medicine, 67, 89-97.

Entertainment Software Association. (2017). Essential facts about the computer and video game industry. Washington, DC. Retrieved April 11, 2019, from: www.theesa.com/article/2017-essential-facts-computervideo-game-industry/.

Eskreis-Winkler, L., Duckworth, A. L., Shulman, E. P., \& Beal, S. (2014). The grit effect: Predicting retention in the military, the workplace, school and marriage. Frontiers in Psychology, 5, 36.

Farley, F. (1986). World of the Type T personality. Psychology Today, 20, 46-52.

Floros, G., \& Siomos, K. (2014). Excessive Internet use and personality traits. Current Behavioral Neuroscience Reports, 1, 19-26.

Gentile, D. (2009). Pathological video-game use among youth ages 8 to 18: A national study. Psychological Science, 20(5), 594-602.

Gonzalez-Bueso, V., Santamaría, J. J., Fernández, D., Merino, L., Montero, E., Jiménez-Murcia, S., et al. (2018). Internet gaming disorder in adolescents: Personality, psychopathology and evaluation of a psychological intervention combined with parent psychoeducation. Frontiers in Psychology, 9, 787.

Griffiths, M. D. (2010). The use of online methodologies in data collection for gambling and gaming addictions. International Journal of Mental Health and Addiction, 8, 8-20.

Griffiths, M. D. \& Davies, M. N. O. (2005). Videogame addiction: Does it exist? In Goldstein, J. \& Raessens, J. (Eds.), Handbook of computer game studies (pp. 359-368). Boston: MIT Press.

Griffiths, M. D., \& Nuyens, F. (2017). An overview of structural characteristics in problematic videogame playing. Current Addiction Reports, 4, 272-283.

Griffiths, M., King, D., \& Demetrovics, Z. (2014). DSM-5 Internet gaming disorder needs a unified approach to assessment. Neuropsychiatry, 4(1), 1-4.

Hu, J., Zhen, S., Yu, C., Zhang, Q., \& Zhang, W. (2017). Sensation seeking and online gaming addiction in adolescents: A moderated mediation model of positive affective associations and impulsivity. Frontiers in Psychology, 8, 699.

Joinson, A. N. (2001). Knowing me, knowing you: Reciprocal self-disclosure in Internet-based surveys. CyberPsychology and Behaviour, 4(5), 587-591.

Kayiș, A. R., Satici, S. A., Yilmaz, M. F., Șimșek, D., Ceyhan, E., \& Bakioğlu, F. (2016). Big five-personality trait and Internet addiction: A meta-analytic review. Computers in Human Behaviour, 63, 35-40.

Kim, E. J., Namkoong, K., Ku, T., \& Kim, S. J. (2008). The relationship between online game addiction and aggression, self-control and narcissistic personality traits. European Psychiatry, 23(3), 212-218. 
Kim, N., Hughes, T. L., Park, C. G., Quinn, L., \& Kong, I. D. (2016). Altered autonomic functions and distressed personality traits in male adolescents with Internet gaming addiction. Cyberpsychology, Behavior and Social Networking, 19(11), 667-673.

Király, O., Griffiths, M. D., Urbán, R., Farkas, J., Kökönyei, G., Elekes, Z., Tamas, D., \& Demetrovics, Z. (2014). Problematic Internet use and problematic online gaming are not the same: Findings from a large nationally representative adolescent sample. Cyberpsychology, Behavior and Social Networking, 17(12), 749-754.

Király, O., Griffiths, M. D., \& Demetrovics, Z. (2015). Internet gaming disorder and the DSM-5: Conceptualization, debates, and controversies. Current Addiction Reports, 2(3), 254-262.

Kırcaburun, K., Jonason, P. K., \& Griffiths, M. D. (2018). The dark tetrad traits and problematic online gaming: The mediating role of online gaming motives and moderating role of game types. Personality and Individual Differences, 135, 298-303.

Klimmt, C., \& Hartmann, T. (2006). Effectance, self-efficacy, and the motivation to play video games. In P. Vorderer \& J. Bryant (Eds.), Playing video games: motives, responses, and consequences (pp. 133-145). Mahwah, New Jersey, United States: Erlbaum.

Kuss, D. J. (2013). Internet gaming addiction: Current perspectives. Psychology Research and Behaviour Management, 6, 125.

Kuss, D. J., \& Griffiths, M. D. (2012). Online gaming addiction in children and adolescents: A review of empirical research. Journal of Behavioral Addictions, 1(1), 3-22.

Laier, C., Wegmann, E., \& Brand, M. (2018). Personality and cognition in gamers: Avoidance expectancies mediate the relationship between maladaptive personality traits and symptoms of Internet-gaming disorder. Frontiers in Psychiatry, 9, 304.

Landers, R. N., \& Lounsbury, J. W. (2006). An investigation of big five and narrow personality traits in relation to Internet usage. Computers in Human Behavior, 22(2), 283-293.

Lee, Y. S., Son, J. H., Park, J. H., Kim, S. M., Kee, B. S., \& Han, D. H. (2017). The comparison of temperament and character between patients with Internet gaming disorder and those with alcohol dependence. Journal of Mental Health, 26(3), 242-247.

Lehenbauer-Baum, M., \& Fohringer, M. (2015). Towards classification criteria for Internet gaming disorder: Debunking differences between addiction and high engagement in a German sample of World of Warcraft players. Computers in Human Behavior, 45, 345-351.

Li, H., Zou, Y., Wang, J., \& Yang, X. (2016). Role of stressful life events, avoidant coping styles, and neuroticism in online game addiction among college students: A moderated mediation model. Frontiers in Psychology, 7, 1794.

McCrae, R. R., \& Costa, P. T. (1987). Validation of the five-factor model of personality across instruments and observers. Journal of Personality and Social Psychology, 52(1), 81-90.

McCrae, R. R., \& Costa, P. T. (1997). Personality trait structure as a human universal. American Psychologist, 52, 509-516.

McKenna, K. Y., \& Bargh, J. A. (2000). Plan 9 from cyberspace: The implications of the Internet for personality and social psychology. Personality and Social Psychology Review, 4(1), 57-75.

Mehroof, M., \& Griffiths, M. D. (2010). Online gaming addiction: The role of sensation seeking, self-control, neuroticism, aggression, state anxiety, and trait anxiety. Cyberpsychology, Behaviour and Social Networking, 13(3), 313-316.

Müller, K. W., Beutel, M. E., Egloff, B., \& Wölfling, K. (2014). Investigating risk factors for Internet gaming disorder: A comparison of patients with addictive gaming, pathological gamblers and healthy controls regarding the big five personalitytraits. European Addiction Research, 20(3), 129-136.

Müller, K. W., Janikian, M., Dreier, M., Wölfling, K., Beutel, M. E., Tzavara, C., Richardson, C., \& Tsitsika, A. (2015). Regular gaming behavior and Internet gaming disorder in European adolescents: Results from a cross-national representative survey of prevalence, predictors, and psychopathological correlates. European Child \& Psychiatry, 24(5), 565-574.

Ozer, D. J., \& Benet-Martinez, V. (2006). Personality and the prediction of consequential outcomes. Annual Review of Psychology, 57, 401-421.

Park, J., Song, Y., \& Teng, C. I. (2011). Exploring the links between personality traits and motivations to play online games. Cyberpsychology, Behavior and Social Networking, 14(12), 747-751.

Parker, J. D. A., Taylor, R. N., Eastabrook, J. M., Schell, S. L., \& Wood, L. M. (2008). Problem gambling in adolescence: Relationships with Internet misuse, gaming abuse and emotional intelligence. Personality and Individual Differences, 45, 174-180.

Petry, N. M., \& O'Brien, C. P. (2013). Internet gaming disorder and the DSM-5. Addiction, 108(7), $1186-1187$.

Pontes, H. M., \& Griffiths, M. D. (2014). Assessment of internet gaming disorder in research: Past and present perspectives. Clinical Research and Regulatory Affairs, 31(24), 35-48. 
Rehbein, F., Kliem, S., Baier, D., Mößle, T., \& Petry, N. M. (2015). Prevalence of Internet gaming disorder in German adolescents: Diagnostic contribution of the nine DSM-5 criteria in a state-wide representative sample. Addiction, 110(5), 842-851.

Ryan, R. M., Rigby, C. S., \& Przybylski, A. (2006). The motivational pull of video games: A self-determination theory approach. Motivation and Emotion, 30, 344-360.

Saunders, J. B., Hao, W., Long, J., King, D. L., Mann, K., Fauth-Bühler, M., et al. (2017). Gaming disorder: Its delineation as an important condition for diagnosis, management, and prevention. Journal of Behavioral Addictions, 6(3), 271-279.

Schimmenti, A., Infanti, A., Badoud, D., Laloyaux, J., \& Billieux, J. (2017). Schizotypal personality traits and problematic use of massively-multiplayer online role-playing games (MMORPGs). Computers in Human Behavior, 74, 286-293.

Schmidt, F. T., Fleckenstein, J., Retelsdorf, J., Eskreis-Winkler, L., \& Möller, J. (2017). Measuring grit: A German validation and a domain-specific approach to grit. European Journal of Psychological Assessment, 1-12. https://doi.org/10.1027/1015-5759/a000407.

Sioni, S. R., Burleson, M. H., \& Bekerian, D. A. (2017). Internet gaming disorder: Social phobia and identifying with your virtual self. Computers in Human Behavior, 71, 11-15.

Stopfer, J. M., Braun, B., Müller, K. W., \& Egloff, B. (2015). Narcissus plays video games. Personality and Individual Differences, 87, 212-218.

Suler, J. (2004). The online disinhibition effect. CyberPsychology and Behavior, 7(3), 312-326.

Tejeiro Salguero, R. A., \& Morán, R. M. B. (2002). Measuring problem video game playing in adolescents. Addiction, 97(12), 1601-1606.

Torres-Rodríguez, A., Griffiths, M. D., Carbonell, X., \& Oberst, U. (2018). Internet gaming disorder in adolescence: Psychological characteristics of a clinical sample. Journal of Behavioral Addictions, 7(3), $707-718$

Trull, T. J. (2012). The five-factor model of personality disorder and DSM-5. Journal of Personality, 80(6), $1697-1720$.

Van Rooij, A. J., Schoenmakers, T. M., Van de Eijnden, R. J., \& Van de Mheen, D. (2010). Compulsive Internet use: The role of online gaming and other Internet applications. Journal of Adolescent Health, 47(1), 51-57.

Walther, B., Morgenstern, M., \& Hanewinkel, R. (2012). Co-occurrence of addictive behaviours: Personality factors related to substance use, gambling and computer gaming. European Addiction Research, 18(4), 167174.

Wang, C. W., Ho, R. T., Chan, C. L., \& Tse, S. (2015). Exploring personality characteristics of Chinese adolescents with Internet-related addictive behaviours: Trait differences for gaming addiction and social networking addiction. Addictive Behaviours, 42, 32-35.

Wittek, C. T., Finserås, T. R., Pallesen, S., Mentzoni, R. A., Hanss, D., Griffiths, M. D., \& Molde, H. (2016). Prevalence and predictors of video game addiction: A study based on a national representative sample of gamers. International Journal of Mental Health and Addiction, 14(5), 672-686.

Yılmaz, O. (2015). The role of personality traits, self-esteem, self-efficacy and locus of control in Internet and gaming dependency, Master's thesis, Eastern Mediterranean University, Gazimağusa, North Cyprus.

Young, K., Pistner, M., O'Mara, J., \& Buchanan, J. (1999). Cyber disorders: The mental health concern for the new millennium. CyberPsychology \& Behavior, 2(5), 475-479.

Zamani, E., Kheradmand, A., Cheshmi, M., Abedi, A., \& Hedayati, N. (2010). Comparing the social skills of students addicted to computer games with normal students. Addiction \& Health, 2(3-4), 59.

Zhou, Y., Li, D., Li, X., Wang, Y., \& Zhao, L. (2017). Big five personality and adolescent Internet addiction: The mediating role of coping style. Addictive Behaviours, 64, 42-48.

Publisher's Note Springer Nature remains neutral with regard to jurisdictional claims in published maps and institutional affiliations. 